\title{
PENGARUH CUSTOMER'S PERCEIVED VALUE TERHADAP PENINGKATAN KINERJA PERUSAHAAN
}

\author{
Priskila Adiasih $^{1^{*}, \text { Saarce Elsye Hatane }}{ }^{2}$ \\ Program Akuntansi Bisnis Universitas Kristen Petra, Surabaya \\ Email: priskila@peter.petra.ac.id; elsyehat@gmail.com \\ * Korespondensi
}

\begin{abstract}
Abstrak: Peningkatan gerai ritel di Indonesia menimbulkan persaingan yang ketat. Nilai yang dirasakan oleh pelanggan menjadi andil terhadap kinerja perusahaan. Penelitian ini bertujuan untuk mengetahui hubungan nilai yang dirasakan pelanggan dengan kinerja perusahaan. Sampel penelitian adalah 35 convenience store dan 40 fashion industry di Surabaya. Hasil uji dengan partial least square menunjukkan bahwa nilai yang dirasakan pelanggan berpengaruh positif terhadap kinerja perusahaan ritel di Surabaya.
\end{abstract}

Kata kunci: Customer's perceived value, corporate image, customer satisfaction, firm performance.

\begin{abstract}
Increasing number of retail store in Indonesia created a fierce competition. The customer's perceived value contributing to firm performance. The purpose of this study was to find correlation costumer's perceived value on store firm's performance. Sample of this study was 35 convenience store and 40 fashion industry in Surabaya. By using partial least square this study found customer's perceived value, reflected by corporate image,had positive influence of store store firm's performance on retail in Surabaya.
\end{abstract}

Keywords: Customer's perceived value, corporate image, customer satisfaction, firm performance.

\section{PENDAHULUAN}

Perkembangan ritel di Indonesia selama tahun 2007 hingga tahun 2016 mengalami peningkatan. Adipudin (2013) menuliskan pada tahun 2007 masih terdapat 10.365 gerai, sedangkan pada tahun 2011 hingga tahun 2012 terjadi peningkatan jumlah ritel menjadi 18.152 gerai yang tersebar di Indonesia. Tribunnews.com melaporkan bahwa pada tahun 2016 pasar ritel bertumbuh sebesar 10-12\% (http://surabaya.tribunnews.com).

Pertumbuhan ritel, terutama convenience store dan industri fashion membuka persaingan yang ketat. Keberhasilan organisasi di lingkungan yang sangat kompetitif ditentukan oleh kemampuan organisasi untuk menciptakan nilai bagi pelanggan, membangun customer satisfaction dan mempertahankan pelanggan selama customer's lifetime (Dlacic dan Kezman, 2014). Oleh karena itu perusahaan perlu membangun corporate image dan menciptakan customer satisfaction agar dapat mendapatkan keuntungan jangka panjang (Ene dan Ozkaya, 2014).

Corporate image, merupakan perceived value dari konsumen, adalah awal yang penting dalam membangun customer satisfaction (Tu et al., 2012). Penelitian Tu et al. (2012) menunjukkan bahwa corporate brand image berpengaruh signifikan pada customer satisfaction sehingga perusahaan secara khusus berfokus untuk membangun profitabilitas jangka panjang dengan pelanggan sebagai keunggul- an kompetitif di pasar. Penelitian lebih lanjut yang dilakukan oleh Tu, et.al (2013) di industri sepatu membuktikan bahwa corporate brand image berpengaruh signifikan terhadap customer satisfaction. Pengaruh positif corporate image terhadap custumer satisfaction juga ditemukan pada hasil penelitian Nezakati et.al (2013) di industri kosmetik. Roche (2014) menunjukkan bahwa corporate image merupakan indikator yang paling berpengaruh signifikan terhadap customer satisfaction dalam sektor bank.

Store corporate image diyakini memiliki pengaruh terhadap store firm performance. Penelitian Rettab et al. (2009), Molina et al. (2009), Lee dan Roh (2012) menunjukkan bahwa corporate reputation merupakan bagian dari store corporate image dan memiliki pengaruh terhadap financial performance. Lee dan Roh (2012) membuktikan bahwa corporate reputation berpengaruh positif terhadap corporate performance. Penelitian Lee dan Roh (2012) menjelaskan bahwa corporate image merupakan bagian dari corporate reputation dan corporate performance merupakan indikator dari firm performance. Weiwei (2007) juga membuktikan corporate image berdampak dalam menciptakan benefit bagi perusahaan.

Williams dan Naumann (2011) menunjukkan bahwa customer satisfaction berpengaruh positif pada total pendapatan. Customer satisfaction berpengaruh terhadap financial performance perusahaan (O'Sullivan dan McCallig, 2012) sehingga disimpulkan 
bahwa customer satisfaction berpengaruh positif terhadap firm value. O’Sullivan dan McCallig (2012) menggunakan earning sebagai indikator financial performance perusahaan yang merupakan cerminan dari firm value. Pengaruh positif customer satisfaction terhadap firm performance juga ditunjukkan dalam penelitian Mittal et.al. (2005). Penelitian Mittal et al. (2005) menemukan bahwa hubungan antara customer satisfaction dengan long-term financial performance adalah positif dan relatif kuat untuk perusahaan yang sukses meningkatkan customer satisfaction dan efisiensi secara bersamaan. Indikator firm performance yang digunakan Mittal et al., (2005) adalah financial performance jangka panjang.

Berdasarkan penelitian-penelitian terdahulu dapat disimpulkan bahwa store firm performance dipengaruhi oleh store corporate image dan customer satisfaction. Penilitian ini meneliti lebih lanjut tentang pengaruh corporate image dan customer satisfaction sebagai variabel intervening terhadap store firm performance pada convenience store dan industri fashion di Surabaya.

\section{TINJAUAN PUSTAKA}

\section{Store Corporate Image dan Customer Satisfaction}

$\mathrm{Tu}$ et al. (2012) menilai corporate image sebagai suatu awal yang penting dari customer satisfaction. Penelitian Tu et al. (2012) menemukan bahwa corporate brand image mempengaruhi customer satisfaction secara signifikan sehingga perusahaan harus secara khusus fokus untuk membangun profitabilitas jangka panjang dengan pelanggan sebagai keunggulan kompetitif di pasar.

Moraga, et al (2008) mendefinisikan satisfaction sebagai respon awal konsumen terhadap perusahaan yang mengutamakan loyalitas konsumen sehingga customer satisfaction didefinisikan sebagai kepuasan dari dalam diri konsumen diiringi dengan respek kepada gerai ritel (Thomas, 2013). Customer satisfaction dapat juga didefinisikan sebagai hubungan kinerja dari sebuah produk atau jasa dengan ekspektasi pelanggan (Ene dan Özkaya, 2014). Huang, et al (2014) berpendapat cutomer satisfaction adalah harapan pelanggan yang harus terpenuhi dari komitmen pelayanan perusahaan agar pembelian ulang oleh konsumen meningkat. Ukuran kepuasan pelanggan dapat diukur melalui expected performance merupakan kinerja perusahaan dalam pelayanan dan fasilitas yang diharapkan pelanggan (Huang et al., 2014).

Martenson (2007) meneliti tentang dampak corporate store image terhadap customer satisfaction di grocery retail dan hasil penelitiannya membukti- kan bahwa yang paling penting bagi customer satisfaction adalah toko sebagai merek karena customer akan merasa puas ketika toko terlihat rapi dan menyenangkan dan juga ketika toko memahami apa yang customer butuhkan. Ene dan Ozkaya (2014) berpendapat bahwa perusahaan perlu menciptakan corporate image yang kuat untuk menjaga agar customer tetap puas. Pada awalnya peningkatan corporate image dan customer satisfaction dianggap sebagai pengeluaran, namun jika perusahaan memiliki pelanggan yang loyal biaya iklan perusahaan akan turun (Ene dan Ozkaya, 2014).

Theodoridis dan Chatzipanagiotou (2009), pada penelitian di toko ritel Yunani, menemukan bahwa ada hubungan antara store image attributes dan customer satisfaction. Total sampel menunjukkan bahwa customer Yunani menilai store image sebagai sesuatu yang signifikan bagi tingkat kepuasan customer tersebut. Penelitian yang dilakukan oleh Roche (2014) menunjukkan bahwa corporate image adalah faktor yang paling signifikan mempengaruhi customer satisfaction dalam sektor perbankan di Sri Lanka.

Image yang positif membawa dampak penting bagi toko (Demirgunes, 2014) sehingga image perlu untuk dibangun dalam pikiran pelanggan untuk menciptakan customer satisfaction karena pelanggan yang merasa puas akan cenderung setia pada toko sehingga hal ini akan membawa keuntungan bagi toko untuk bertahan di pasar. Hasil penelitiannya menunjukkan bahwa terdapat pengaruh positif antara store image dan customer satisfaction.

Berdasarkan hasil-hasil penelitian di atas, hipotesa pertama dalam penelitian ini adalah:

H1: Store corporate image berpengaruh postitif dan signifikan terhadap customer satisfaction pada convenience store dan toko ritel fashion di Surabaya

\section{Customer Satisfaction dengan Store Firm Perfor- mance}

Customer satisfaction berpengaruh positif dan signifikan terhadap profitabilitas dan firm's financial performance (Au dan Yeung 2013,Williams dan Naumann 2011, Keisidou et al., 2013). Hasil penelitian Williams dan Naumann (2011) menunjukkan bahwa ada hubungan positif antara customer satisfaction dan total pendapatan. Penelitian O'Sullivan dan McCallig (2012) menemukan bahwa customer satisfaction memiliki dampak pada nilai perusahaan.

Upaya meningkatkan kepuasan pelanggan tidak cukup sebagai strategi untuk keunggulan bersaing perusahaan dalam jangka panjang. Financial performance dapat ditingkatkan melalui peningkatan 
customer satisfaction dengan cara menciptakan efisiensi dan sistem manajemen yang dinamis (Nayebzadeh et.al., 2013).

Mittal et al. (2005) berpendapat bahwa fokus untuk meningkatkan pendapatan hanya melalui customer satisfaction atau hanya melakukan efisiensi melalui pengurangan biaya saja merupakan strategi yang kurang optimal untuk kinerja jangka panjang. Jika perusahaan hanya fokus untuk meningkatkan kepuasan maka hal itu hanya akan meningkatkan kinerja jangka pendek.

Berdasarkan hasil-hasil penelitian di atas maka hipotesis kedua penelitian ini adalah:

$\mathrm{H} 2$ : Customer satisfaction berpengaruh positif dan signifikan terhadap store firm performance pada convenience store dan toko ritel fashion di Surabaya.

\section{Store Corporate Image dengan Store Firm Perfor- mance}

Tang (2007) menyatakan bahwa corporate image yang baik dapat digunakan sebagai sarana yang efektif untuk memprediksi hasil proses produksi di bidang jasa dan mampu menjadi alat isyarat untuk mengukur kemampuan suatu perusahaan dalam memenuhi kebutuhan pelanggannya.

Penelitian yang dilakukan oleh Molina et al. (2009) menemukan bahwa corporate reputation merupakan bagian dari store corporate image dan memiliki pengaruh terhadap financial performance. Performance adalah tolak ukur kinerja keuangan perusahaan yang dihasilkan dari keputusan manajemen (Carton, 2004). Rettab et al. (2009) menemukan hubungan positif antara image perusahaan terhadap kinerja keuangan. Image dalam penelitian ini diwakili oleh corporate social responsibility (CSR) sebagai corporate reputation yang dilakukan oleh perusahaan atas dasar moral. CSR juga dilakukan untuk menyampaikan informasi bahwa perusahaan bertanggung jawab atas lingkungan sehingga perusahaan meningkatkan keunggulan bersaing melalui image yang ditunjukkan.

Akbari, Rostami dan Viesmoradi (2013) berpendapat bahwa pengukuran subjektif terhadap kinerja perusahaan (organizational performance) lebih mempermudah penelitian untuk mendeteksi faktor-faktor yang memengaruhi store firm performance. Lee dan Roh (2012) menunjukkan hasil penelitian bahwa store corporate image berpengaruh terhadap financial performance.
Berdasarkan berbagai penjelasan di atas, hipotesa ketiga dalam penelitian ini adalah:

H3: Store corporate image berpengaruh positif dan signifikan terhadap store firm performance pada convenience store dan toko ritel fashion di Surabaya.

\section{METODE PENELITIAN}

Populasi dalam penelitian ini adalah toko ritel convenience store dan industri fashion di kota Surabaya. Peneliti menggunakan data primer yang diperoleh melalui kuesioner. Kuesioner diberikan kepada manajemen dan konsumen di toko ritel dalam industri fashion dan convenience store di Surabaya.

Sampel yang diambil peneliti dalam penelitian ini adalah 75 gerai ritel di Surabaya. Pengisian kuesioner untuk satu gerai akan diwakili oleh minimal 5 orang responden yang merupakan konsumen toko tersebut dan 1 orang manajer atau perwakilan gerai. Skala pengukuran kuesioner yang akan digunakan dalam penelitian ini adalah skala pengukuran interval. Responden akan diminta untuk memilih jawaban sesuai ranking yang ada menurut pendapat responden.

Kelompok pernyataan kuesioner mewakili variabel bebas, variabel perantara dan variabel terikat. Responden akan memberikan respon dalam skala likert yaitu 1 (Sangat Tidak Setuju) - 5 (Sangat Setuju). Kuisioner yang disebarkan terdiri dari tiga bagian, yaitu:

1. Variabel bebas: Corporate image, diadopsi dari Ene dan Özkaya, 2014. Indikator yang digunakan adalah store layout, store prestige, service quality of store, products, in-store promotion, support services and equipment.

2. Variabel perantara: Customer satisfaction yang diadopsi dari Huang et al., 2014. Indikator yang digunakan adalah expected performance.

3. Variabel terikat: Store firm performance yang diadopsi dari Akbari et al., 2013. Indikator yang digunakan adalah the amount of income, the growth of income, the growth of sales, the amount of profitability, the growth of profit, The comparison of growth of profit, the comparison of number of customer, the growth of number of customer, the comparison of number of customer

Teknik analisis data yang digunakan dalam penelitian ini adalah Partial Least Square (PLS) yang merupakan bagian dari SEM.

Model analisis hipotesis penelitian ini terlihat pada Gambar 1. 


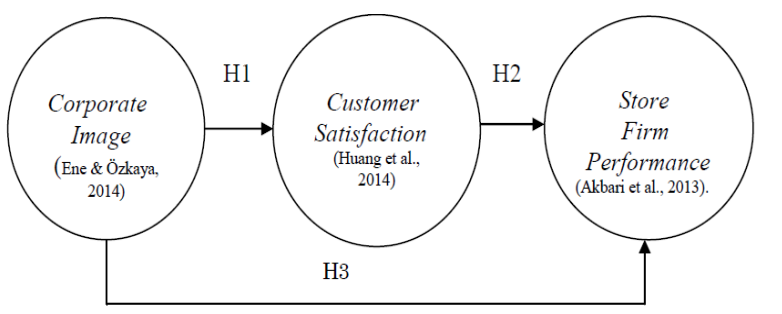

Gambar 1. Model Analisis Hipotesis

\section{HASIL PENELITIAN}

\section{Analisis Validitas dan Realibilitas}

Convergent validity menunjukkan bahwa setiap konstruk memiliki korelasi yang tinggi. Indikator dapat dikatakan memenuhi convergent validity apabila memiliki nilai outer loading $>0.5$ dan nilai thitung >1.96. Tabel 1 menunjukkan bahwa nilai outer loading masing-masing indikator penelitian > 0.5 dan t-hitung $>1.96$. Hal ini menunjukkan bahwa indikator-indikator pada penelitian ini telah memenuhi kriteria convergent validity yang diharapkan.

Tabel 1. Nilai Outer Loading

\begin{tabular}{|c|c|c|c|}
\hline & $\begin{array}{c}\text { Original } \\
\text { Sample } \\
\text { (O) }\end{array}$ & $\begin{array}{c}\text { Standard } \\
\text { Deviation } \\
(\mathrm{STDEV})\end{array}$ & $\begin{array}{c}\text { T Statistics } \\
(|\mathrm{O} / \mathrm{STERR}|\end{array}$ \\
\hline$\overline{\text { CI1 <- Image }}$ & 0.861229 & 0.021826 & 39.459204 \\
\hline $\mathrm{CI} 2<-$ Image & 0.863912 & 0.018689 & 46.224798 \\
\hline CI3 <- Image & 0.818357 & 0.025834 & 31.678025 \\
\hline CI4 <- Image & 0.795223 & 0.028107 & 28.292552 \\
\hline CI5 <- Image & 0.871163 & 0.016084 & 54.163501 \\
\hline CI6 <- Image & 0.800097 & 0.028563 & 28.011228 \\
\hline EP1 <- Exp Perfom & 0.597716 & 0.079704 & 7.499177 \\
\hline EP2 <- Exp Perfom & 0.765732 & 0.030642 & 24.989981 \\
\hline EP3 <- Exp Perfom & 0.845882 & 0.017802 & 47.515279 \\
\hline EP4 <- Exp Perfom & 0.885917 & 0.013878 & 63.834597 \\
\hline $\begin{array}{l}\text { FP1 <- Firm } \\
\text { Perform }\end{array}$ & 0.649188 & 0.039075 & 16.613761 \\
\hline $\begin{array}{l}\text { FP2 <- Firm } \\
\text { Perform }\end{array}$ & 0.747551 & 0.021667 & 34.501467 \\
\hline $\begin{array}{l}\text { FP3 <- Firm } \\
\text { Perform }\end{array}$ & 0.753183 & 0.026298 & 28.640518 \\
\hline $\begin{array}{l}\text { FP4 <- Firm } \\
\text { Perform }\end{array}$ & 0.707735 & 0.035162 & 20.1281 \\
\hline $\begin{array}{l}\text { FP5 <- Firm } \\
\text { Perform }\end{array}$ & 0.66239 & 0.026297 & 25.189223 \\
\hline $\begin{array}{l}\text { FP6 <- Firm } \\
\text { Perform }\end{array}$ & 0.778534 & 0.022764 & 34.199604 \\
\hline $\begin{array}{l}\text { FP7 <- Firm } \\
\text { Perform }\end{array}$ & 0.720258 & 0.024176 & 29.791783 \\
\hline $\begin{array}{l}\text { FP8 <- Firm } \\
\text { Perform }\end{array}$ & 0.739376 & 0.023107 & 31.998296 \\
\hline $\begin{array}{l}\text { FP9 <- Firm } \\
\text { Perform }\end{array}$ & 0.793185 & 0.020363 & 38.952445 \\
\hline
\end{tabular}

Discriminant validity menunjukkan bahwa indikator yang mengukur masing-masing konstruk tidak memiliki korelasi yang tinggi. Suatu indikator dikatakan memenuhi discriminant validity jika nilai cross loading indikator terhadap variabelnya lebih besar dibandingkan variabel yang lainnya.

Tabel 2. Nilai Cross Loading Factor

\begin{tabular}{cccc}
\hline Indicators & Image & Exp Perfom & Firm Perform \\
\hline CI1 & 0.861229 & 0.678036 & 0.36058 \\
CI2 & 0.863912 & 0.724742 & 0.422021 \\
CI3 & 0.818357 & 0.771755 & 0.526964 \\
CI4 & 0.795223 & 0.646328 & 0.377296 \\
CI5 & 0.871163 & 0.704201 & 0.424661 \\
CI6 & 0.800097 & 0.661782 & 0.436692 \\
EP1 & 0.491308 & 0.597716 & 0.156653 \\
EP2 & 0.672856 & 0.765732 & 0.400887 \\
EP3 & 0.700753 & 0.845882 & 0.452135 \\
EP4 & 0.730014 & 0.885917 & 0.413373 \\
FP1 & 0.280055 & 0.334225 & 0.649188 \\
FP2 & 0.422103 & 0.394153 & 0.747551 \\
FP3 & 0.386617 & 0.396149 & 0.753183 \\
FP4 & 0.347511 & 0.394929 & 0.707735 \\
FP5 & 0.296503 & 0.220471 & 0.66239 \\
FP6 & 0.371141 & 0.316958 & 0.778534 \\
FP7 & 0.291574 & 0.252925 & 0.720258 \\
FP8 & 0.428521 & 0.332065 & 0.739376 \\
FP9 & 0.470594 & 0.416299 & 0.793185 \\
\hline
\end{tabular}

Tabel 2 menunjukkan bahwa secara umum indikator yang menyusun semua variabel dalam penelitian telah memenuhi discriminant validity karena memiliki nilai outer loading terbesar untuk variabel yang dibentuknya.

Uji realibilitas dilakukan untuk menguji konsistensi dan akurasi masing-masing indikator konstruk. Uji reliabilitas menggunakan uji composite reliability dan cronbach alpha. Suatu konstruk dikatakan memenuhi composite reliability jika memiliki nilai composite reliability $>0.7$ dan cronbach alpha $>0.6$.

Tabel 3. Nilai Composite reliability dan Cronbach Alpha

\begin{tabular}{ccc}
\hline Indicator & Composite Reliability & Cronbachs Alpha \\
\hline Exp Perfom & 0.860278 & 0.782164 \\
Firm Perform & 0.910634 & 0.889567 \\
Image & 0.932712 & 0.913309 \\
\hline
\end{tabular}

Tabel 3 menunjukkan bahwa nilai composite reliability dari setiap variabel penelitian $>0.7$ dan nilai cronbach alpha $>0.6$ sehingga dapat disimpulkan bahwa masing-masing indikator telah memenuhi kriteria uji reliabilitas.

\section{Inner Model dan Goodness of Fit}

Inner model merupakan model struktural untuk memprediksi hubungan kausalitas antar variabel. 
Nilai $R$-Square digunakan untuk mengukur tingkat variasi perubahan variabel independen terhadap variabel dependen. Semakin tinggi nilai $R$-Square berarti semakin baik model prediksi dari model penelitian yang diajukan. Tabel 4 menunjukkan nilai $R$-Square sebagai berikut.

Tabel 4. Nilai $R$-Square

\begin{tabular}{lc}
\hline \multicolumn{1}{c}{ Indicator } & R Square \\
\hline Exp Perfom & 0.70399 \\
Firm Perform & 0.269865 \\
Image & \\
\hline
\end{tabular}

Nilai $R$-Square untuk customer satisfaction sebesar 0.70399, berarti corporate image dapat mempengaruhi customer satisfaction sebesar $70.4 \%$. Firm performance memiliki nilai $R$-Square sebesar 0.269865 berarti bahwa corporate image dan customer satisfaction dapat mempengaruhi sebesar 26.9\% tingkat store firm performance dari perusahaan ritel yang bersangkutan.

Goodness of Fit dilakukan melalui pengujian Stone-Geisser atau $\mathrm{Q}^{2}$. Uji Stone-Geisser $\left(\mathrm{Q}^{2}\right)$ digunakan untuk mengukur seberapa baik nilai observasi dihasilkan oleh model dan juga estimasi parameternya. Dari nilai $R$-Square diatas, dapat diketahui nilai $\mathrm{Q}^{2}$ sebagai berikut:

$$
\begin{aligned}
\text { Nilai } Q^{2} & =1-[(1-0.70399) \times(1-0.269865] \\
& =0.783873
\end{aligned}
$$

Dari hasil perhitungan diketahui nilai $\mathrm{Q}^{2}$ sebesar 0.784 , berarti besarnya keragaman dari data penelitian yang dapat dijelaskan oleh model struktural adalah sebesar $78.4 \%$, dan $21.6 \%$ sisanya dijelaskan oleh faktor lain di luar model. Berdasarkan hasil ini model struktural pada penelitian memiliki goodness of fit yang baik.

Tabel 5. Uji Hipotesis

\begin{tabular}{lcccc}
\hline & $\begin{array}{c}\text { Original } \\
\text { Sample } \\
(\mathrm{O})\end{array}$ & $\begin{array}{c}\text { Sample } \\
\text { Mean } \\
(\mathrm{M})\end{array}$ & $\begin{array}{c}\text { Standard } \\
\text { Deviation } \\
(\mathrm{STDEV})\end{array}$ & $\begin{array}{c}\text { T Statistics } \\
(\mid \mathrm{O} / \mathrm{STERR})\end{array}$ \\
\hline Image -> Exp & 0.8390410 .841715 & 0.023037 & 36.422191 \\
Perfom & & & \\
$\begin{array}{l}\text { Exp Perfom -> } \\
\text { Firm Perform }\end{array}$ & 0.15167 & 0.155004 & 0.073854 & 2.053635 \\
$\begin{array}{l}\text { Image -> Firm } \\
\text { Perform }\end{array}$ & 0.3856330 .385595 & 0.072567 & 5.314157 \\
\hline
\end{tabular}

Tabel 5 menunjukkan hasil uji hipotesis. Hipotesis penelitian dapat diterima jika nilai $\mathrm{t}$ hitung $(t$-statistic) $>\mathrm{t}$ tabel pada tingkat kesalahan $(\alpha) 5 \%$ yaitu 1.96 .

\section{PEMBAHASAN}

Penelitian ini menunjukkan bahwa corporate image berpengaruh postitif dan signifikan terhadap customer satisfaction. Hasil ini mendukung penelitian terdahulu oleh Ene dan Özkaya (2014), Tu et al. (2013), Nezakati et al. (2013), Hamidizadeh et al. (2013) dan Roche (2014). Nilai $R$-Square sebesar 0.70399 pada Tabel 4 berarti bahwa corporate image mempengaruhi customer satisfaction sebesar $70.39 \%$. Hal ini berarti konsumen merasa bahwa kepuasan yang dirasakan ditunjang oleh corporate image yang bagus dari toko ritel tersebut. Nilai 0.871 pada Gambar 2 menunjukkan bahwa store corporate image tertinggi cenderung dikaitkan dengan indikator in-store promotion (CI5) dari toko ritel sehingga dapat disimpulkan bahwa indikator yang paling mempengaruhi store corporate image adalah in-store promotion.

Tabel 6. Perbandingan Pengaruh Tidak Langsung dengan Pengaruh Langsung

\begin{tabular}{lcc}
\hline \multicolumn{1}{c}{ Pengaruh } & $\begin{array}{l}\text { Pengaruh } \\
\text { langsung }\end{array}$ & Pengaruh tidak langsung \\
\hline $\begin{array}{l}\text { Image -> } \\
\text { Firm Perfom }\end{array}$ & 0.386 & $0.839041 \times 0.15167=0.127257348$ \\
$\begin{array}{l}\text { Exp Perfom } \\
\text { - Firm }\end{array}$ & & \\
Perform & 0.15167 \\
Image -> & \\
Firm & \\
Perform & 0.385633 \\
\hline
\end{tabular}

Store firm performance dipengaruhi positif dan signifikan oleh customer satisfaction sesuai dengan hasil penelitian oleh Mittal et al. (2005), Williams dan Naumann (2011), O'Sullivan dan McCallig (2012), Nayebzadeh et al. (2013). Nilai expected performance tertinggi adalah EP4 sebesar 0.886. Hal ini menunjukkan bahwa convenient store berpengaruh tinggi terhadap store firm performance.

Store corporate image berpengaruh positif dan signifikan terhadap store firm performance sesuai dengan hasil penelitian Tang (2007) dan Rettab et al. (2009) yang menyatakan bahwa store corporate image berpengaruh positif signifikan terhadap store firm performance. Nilai financial performance tertinggi adalah FP9 sebesar 0.793 menunjukkan bahwa pertumbuhan pelanggan lebih tinggi dari pada kompetitor.

$\mathrm{Q}^{2}$ pada penelitian ini adalah sebesar $78.4 \%$ menunjukkan bahwa pengaruh store corporate image terhadap store firm performance melalui customer satisfaction adalah kuat. Berdasarkan Tabel 6 terlihat 
bahwa pengaruh langsung store corporate image terhadap store firm performance adalah sebesar 0.386, sedangkan pengaruh tidak langsung store corporate image terhadap store firm performance melalui customer satisfaction adalah sebesar 0.12725735 . Customer satisfaction yang diproksikan dengan expected firm performance dapat menjadi mediasi hubungan antara store corporate image dengan store firm performance namun kemampuan mediasi costumer satisfaction lebih kecil dibandingkan pengaruh langsung.

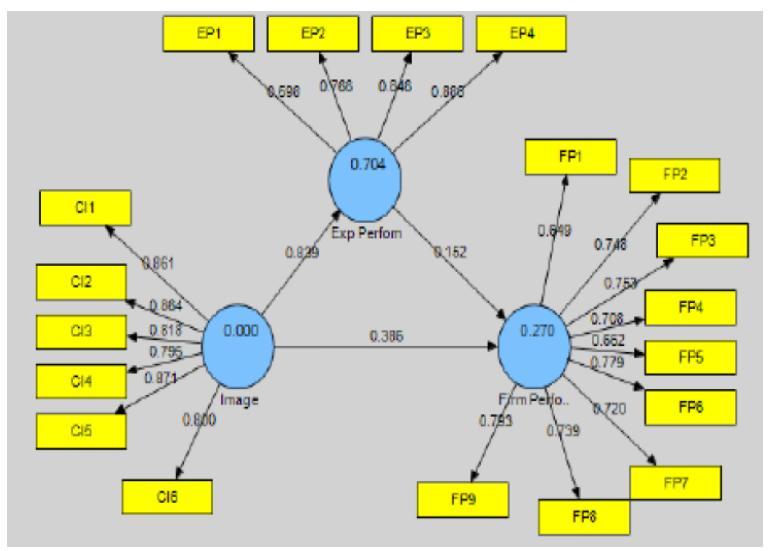

Gambar 2. Model Struktural PLS

\section{KESIMPULAN DAN IMPLIKASI}

Penelitian ini membuktikan bahwa store corporate image dan customer satisfaction memengaruhi store firm performance sehingga disimpulkan bahwa customer satisfaction memiliki peranan dalam hubungan store corporate image ke store firm performance. Hal ini menunjukkan bahwa image perusahaan yang dipersepsikan oleh konsumen lebih kuat dalam meningkatkan kinerja perusahaan.

Expected performance pelanggan terhadap perusahaan adalah kemudahan dalam melakukan transaksi pembelian, pelanggan merasa nyaman dan senang berbelanja. Perusahaan dapat mempertahankan atau meningkatkan expected performance dengan menyediakan beragam pilihan produk fashion yang terbaru agar pelanggan senang berbelanja. Kenyamanan pelanggan dapat ditingkatkan dengan keramahan pegawai, pengaturan barang, lay out dan display toko. Perusahaan dapat menyediakan berbagai metoda pembayaran (bank transfer, kartu kredit, debit online, maupun tunai), layanan pengantaran barang, dan layanan vermak baju yang dibeli (khususnya bagi fashion).

Pelanggan memiliki persepsi bahwa harga produk yang dibeli sesuai dengan nilai dan manfaat produk. Promosi yang bagus, menarik dan memuas- kan dapat membentuk image perusahaan semakin baik dalam persepsi pelanggan. Oleh karena itu perusahaan ini harus meningkatkan kualitas layanannya. Indikasi yang mewakili corporate image di penelitian ini adalah kemampuan perusahaan melakukan promosi di dalam toko. Bentuk in-store promotion antara lain memberikan bonus pembelian, kupon potongan harga, volume discount. Image in-store promotion perusahaan yang telah dipersepsikan dengan sangat baik oleh pelanggan dapat berdampak terhadap pertumbuhan pelanggan. Pertumbuhan pelanggan yang lebih tinggi dari kompetitor sebagai akibat dari image perusahaan yang baik akhirnya dapat berdampak pada kinerja keuangan perusahaan.

Responden penelitian ini terbatas pada manajemen dan pelanggan dari industri ritel convenience store dan fashion di Surabaya. Bentuk bisnis perusahaan terbatas pada Business to Customer (B2C) sehingga penelitian berikutnya dapat mengembangkan sampel pada industri dan lokasi lainnya. Penelitian selanjutnya dapat menganalisa faktor-faktor lain sebesar $21.62 \%$ di luar $\mathrm{Q}^{2}$ sebesar $78.38 \%$, yang dapat mempengaruhi store firm performance. Beberapa variable yang dapat digunakan sebagai mediasi image perusahaan dalam memengaruhi financial performance antara lain word of mouth (Wang et. al, 2012), teknologi informasi (Oh et. al, 2012).

\section{DAFTAR PUSTAKA}

Adipudin. (2013, January 3). Brand Switching Analysis dalam Industri Ritel Modern. Marketing Cyber Media. Retrieved April 05, 2015, from http://www.marketing.co.id/brand-switchinganalysis-dalam-industri-ritel-modern/

Akbari, P., Rostami, R., \& Veismoradi, A. (2013). The Analysis Impact of Human Resource Management and Intellectual Capital on Organizational Performance in Physical Education Organization of Iran (Case Study: Physical Education General Department of Kermanshah). International Journal of Sport Studies, 3(3), 263-273.

$\mathrm{Au}, \mathrm{A}$. K. M. \& Yeung, M. C. H. (2013). Customer Satisfaction and Profitability: A Dynamic Panel Data Analysis. Journal of Business Administration Research, 2(2), 54-60.

Carton, R. B. (2004). Measuring Organizational Performance: An Exploratory Study. Unpublished undergraduate thesis, The University of Georgia, Athens.

Demirgunes, B. K. (2014). The Antecedents of Store Image and Customer Satisfaction. International Journal of Research in Business and Social Science, 3(3), 48-62. 
Dlacic, J., \& Kezman, E. (2014). Exploring relationship between brand equity and customer loyalty on pharmaceutical market. Economic and Business Review, 16(2), 121-131.

Ene, S., \& Ozkaya, B. (2014). A Study on Corporate Image, Customer Satisfaction and Brand Loyalty in the Context of Retail Stores. Asian Social Science, 10(14), 52-66.

Hamidizadeh, M. R., Jazani, N., Hajikarimi, A., \& Ebrahim, A. (2013). A Proposed Model for Explanation of Influential Factors on Customer Satisfaction in Banking Industry. Interdisciplinary Journal of Contemporary Research in Business, 3(4), 136-143.

Huang, C. C., Yen, S. W., Liu, C. Y., \& Chang, T. P. (2014). The Relationship Among Brand Equity, Customer Satisfaction, and Brand Resonance to Repurchase Intention of Cultural and Creative Industries in Taiwan. The International Journal of Organizational Innovation, 6(3), 106-120.

Keisidou, E., Sarigiannidis, L., Maditinos, D. I., \& Thalassinos, E. I. (2013). Customer satisfaction, loyalty and financial performance: A holistic approach of the Greek banking sector. International Journal of Bank Marketing, 31(4), 259288.

Lee, J., \& Roh, J. J. (2012). Revisiting Corporate Reputation and Firm Performance Link. Benchmarking: An International Journal, 19(4/5), 649-664.

Martenson, R. (2007). Corporate Brand Image, Satisfaction and Store Loyalty: A Study of the Store as a Brand, Store Brands and Manufacturer Brands. International Journal of Retail \& Distribution Management, 35(7), 544-555.

Mittal, V., Anderson, E. W., Sayrak, A., \& Tadikamalla, P. (2005). Dual Emphasis and the LongTerm Financial Impact of Customer Satisfaction. Marketing Science, 24(4), 544-555.

Molina-Azorin, J. F., Claver-Cortes, E., LopezGamero, M. D., \& Tari, J. J. (2009). Green management and financial performance: a literature review. Management Decision, 47(7), 10801100.

Moraga, E. T., Parraga, A. Z. V., \& González, J. Z. (2008). Customer Satisfaction and Loyalty: Start with the Product, Culminate with the Brand. Journal of Consumer Marketing, 25(5), 302313.

Nayebzadeh, S., Jalaly, M., \& Shamsi, H. M. (2013). The relationship between customer satisfaction and loyalty with the bank performance in IRAN. International Journal of Academic Research in Business and Social Sciences, 3(6), 114-124.
Nezakati, H., Yen, C. P., \& Akhoundi, M. (2013). Antecedents Impact on Brand Loyalty in Cosmetics Industry. Journal of Applied Sciences, 13(1), 126-132.

Oh, Lih-Bin, Hock-Hai Teo, Vallabh Sambamurthy. (2012). The Effects of Retail Channel Integration Through The Use of Information Technologies on Firm Performance. Journal of Operations Management 30, 368-381

O'Sullivan, D., \& McCallig, J. (2012). Customer Satisfaction, Earnings and Firm Value. European Journal of Marketing, 46(6), 827-843.

Rettab, B., Brik, A. B., \& Mellahi, K. (2009). A Study of Management Perceptions of The Impact of Corporate Social Responsibility on Organisational Performance in Emerging Economies: The Case of Dubai. Journal of Business Ethics, 89(3), 371-390.

Roche, I. D. (2014). An Empirical Investigation of Internet Banking Service Quality, Corporate Image and the Impact on Customer Satisfaction; With Special Reference to Sri Lankan Banking Sector. Journal of Internet Banking and Commerce, 19(2), 1-18.

Tang, W. W. (2007). Impact of Corporate Image and Corporate Reputation on Customer Loyalty: A Review. Management Science and Engineering, 1(2), 57-62.

Theodoridis, P. K., \& Chatzipanagiotou, K. C. (2009). Store image attributes and customer satisfaction across different customer profiles within the supermarket sector in Greece. European Journal of Marketing, 43(5/6), 708-734.

Thomas, S. (2013). Linking Customer Loyalty to Customer Satisfaction and Store Image: A Structural Model for Retail Stores Image: A Structural Model for Retail Stores. Research Paper of Indian Institute of Management Calcutta, 40(2), 15-25.

Tribunnews (2016). Bisnis Ritel Naik 12 Persen, Tunjungan Plaza Perluas Pasar. Retrieved October 09, 2016. http://surabaya.tribunnews. com/2016/03/13/bisnis-ritel-naik-12-persentunjungan-plaza-perluas-pasar

Tu, Y. T., Wang, C. M., \& Chang, H. C. (2012). Corporate brand image and customer satisfaction on loyalty: An empirical study of starbucks coffee in Taiwan. Journal of Social and Development Sciences, 3(1), 24-32.

Tu, Y. T., Li, M. L., \& Chih, H. C. (2013). An Empirical Study of Corporate Brand Image, Customer Perceived Value and Satisfaction on Loyalty in Shoe Industry. Journal of Economics and Behavioral Studies, 5(7), 469-483. 
Wang, Youwei, Shan Wang, Yulin Fang, Patrick Y.K. Chau. (2012). Store Survival in Online Marketplace: An Empirical Investigation. Decision Support Systems, 1-12.

Weiwei, T. T. (2007). Impact of Corporate Image and Corporate Reputation on Customer Loyalty: A
Review. Management Science and Engineering, 1(2), 57-62.

Williams, P., \& Naumann, E. (2011). Customer Satisfaction and Business Performance: A FirmLevel Analysis. Journal of Services Marketing, 25(1), 20-32. 